January 1998

\title{
Gabapentin in the Treatment of Bipolar Disorder
}

\author{
Wendy M. Waits \\ Uniformed Services University of Health Sciences \\ Donald P. Hall Jr., M.D. \\ Walter Reed Army Medical Center; Uniformed Services University
}

Follow this and additional works at: https://jdc.jefferson.edu/jeffjpsychiatry

Part of the Psychiatry Commons

Let us know how access to this document benefits you

\section{Recommended Citation}

Waits, Wendy M. and Hall, Donald P. Jr., M.D. (1998) "Gabapentin in the Treatment of Bipolar Disorder," Jefferson Journal of Psychiatry. Vol. 14 : Iss. 1 , Article 5.

DOI: https://doi.org/10.29046/JJP.014.1.004

Available at: https://jdc.jefferson.edu/jeffjpsychiatry/vol14/iss1/5

This Article is brought to you for free and open access by the Jefferson Digital Commons. The Jefferson Digital Commons is a service of Thomas Jefferson University's Center for Teaching and Learning (CTL). The Commons is a showcase for Jefferson books and journals, peer-reviewed scholarly publications, unique historical collections from the University archives, and teaching tools. The Jefferson Digital Commons allows researchers and interested readers anywhere in the world to learn about and keep up to date with Jefferson scholarship. This article has been accepted for inclusion in Jefferson Journal of Psychiatry by an authorized administrator of the Jefferson Digital Commons. For more information, please contact: JeffersonDigitalCommons@jefferson.edu. 


\title{
Gabapentin in the Treatment of Bipolar Disorder
}

\author{
Wendi M. Waits and Donald P. Hall, MD
}

\begin{abstract}
Gabapentin, a relatively new anti-epileptic drug (AED), is emerging as a therapeutic option for treatment refractory and rapid-cycling bipolar illnesses. Pharmacotherapy for bipolar disorders traditionally involves valproate, carbamazapine, or lithium, drugs which are associated with numerous adverse effects. Conversely, gabapentin has an attractive pharmacokinetics profile and relatively few side effects. There are no large randomized controlled clinical trials to date examining gabapentin's role in mood stabilization. However, informal reports have cited encouraging results in up to $80 \%$ of patients and general tolerance to side effects. These findings make the new drug a possible choice for patients who have failed to respond to traditional agents or developed side effects which interfere with medication compliance.
\end{abstract}

\section{METHODOLOGY}

A literature search of the Medline and Silver Platter databases was performed. English language articles published between 1990-1997 were reviewed. Keywords "gabapentin," "bipolar," "epilepsy," and "psychiatry" were used in various combinations. All articles which addressed the use of gabapentin in human subjects were considered. Review of citations in these articles led to further references to the clinical use of gabapentin. All citations related to the use of gabapentin in the treatment of affective disorders are included in this review. Other articles which address clinically useful pharmacological issues are also included.

\section{CHEMISTRY}

Gabapentin (Neurontin) is a cyclic gamma-amino butyric acid (GABA) analogue which may alter GABA transmission in the central nervous system (1). The molecule incorporates a lipophilic cyclohexane ring into its structure, which allows gabapentin, unlike GABA, to cross the blood-brain barrier. Pharmacokinetic and pharmacodynamic investigations have largely relied on study of animals. The drug was initially developed as a spasmolytic but demonstrated effective anticonvulsant properties, and thus entered the pharmaceutical market as an AED (2).

Early research into gabapentin's mechanism of action failed to provide strong evidence of GABAergic activity. It does not appear to significantly bind to GABA-A, GABA-B, glutamate, glycine, or benzodiazapine receptors; it does not affect voltage 


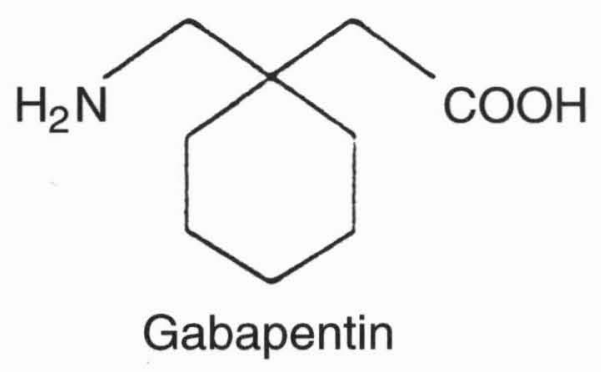

FIGURE 1. Structure of Gabapentin

gated sodium or calcium channels, and it does not elevate GABA concentration in nerve terminals $(1,3)$. However, administration of gabapentin has been associated with increased GABA concentration in the substantia nigra, a region repeatedly indicated in the activity of GABAergic anticonvulsants (4).

Gabapentin is transported across enteric membranes and most likely through the blood-brain barrier and into neurons by an L-amino acid carrier $(2,5)$. Its binding site has been recently identified as a subunit of a calcium channel on neuronal cell surfaces $(3,6)$. Gabapentin increases the rate of synthesis and accumulation of GABA, decreases the release of monoamines (dopamine, norepinephrine, and serotonin), and weakly inhibits GABA-transaminase, an enzyme which degrades GABA into other amino acids $(3,4)$.

\section{PHARMACOKINETICS}

Gabapentin is becoming popular among practitioners due to its favorable pharmacokinetics profile. It is efficiently absorbed in the gut following oral ingestion. The drug has a half-life of 5-9 hours, reaches peak plasma concentration in 2-3 hours, and achieves steady state in 1-2 days. It is water-soluble and non-protein-bound, but is distributed throughout the body (including the CNS) by means of protein transport. Gabapentin is not metabolized, is completely eliminated by the kidneys, and does not interact with hepatic enzymes. These qualities theoretically eliminate potential interactions with other medications $(2,5,7)$.

\section{CLINICAL USE}

Controlled clinical trials of gabapentin in the treatment of psychiatric disorders have not been performed. Several anecdotal reports of use exist in the medical literature (8-12), including a growing number of documents pertaining to gabapentin's role in bipolar illness. However, most data regarding the drug's efficacy and safety appear in reports of gabapentin's use as an anticonvulsant. This information has served as a valuable guide to preliminary studies in the mental health arena.

Three large randomized controlled clinical trials have evaluated the efficacy and safety of adjunctive gabapentin therapy in treating refractory epilepsy: the UK 
Gabapentin Study Group (1990), the US Gabapentin Study Group No. 5 (1993), and the International Gabapentin Study Group (1994). Drug dosages ranged from 600 $\mathrm{mg} / \mathrm{d}$ to $1800 \mathrm{mg} / \mathrm{d}$, with the most effective dosing regimen reported to be $1800 \mathrm{mg} / \mathrm{d}$. The percentages of patients in whom seizure frequency decreased at least $50 \%$ (responders) were 25\%, 26\%, and 28\%, respectively (19). Morris has since reported a retrospective analysis of 100 patients on gabapentin, 72 of whom experienced a greater than $50 \%$ reduction in seizure frequency. The mean drug dose in this patient population was $2107 \mathrm{mg} / \mathrm{d}$; 37 of the 72 who responded (51\%) were taking $1800 \mathrm{mg} / \mathrm{d}$ or less. The remaining patients took $1800-3600 \mathrm{mg} /$ day (20).

Data regarding the role of gabapentin in the treatment of bipolar disorders is preliminary, yet encouraging. In one retrospective study of bipolar patients who had failed to respond to traditional mood stabilizers or developed intolerable side effects from these agents, $92 \%$ responded positively to gabapentin (14). All other published studies, consisting of open trials which have included gabapentin both as monotherapy and in addition to other psychotropic medications, have reported effective improvement in the majority of patients $(13,15,17,18)$. Most patients have displayed noticeable improvement in cycling activity with $200-3600 \mathrm{mg} / \mathrm{d}$, though doses as low as $33 \mathrm{mg} / \mathrm{d}$ and as high as $4900 \mathrm{mg} / \mathrm{d}$ have been reported $(13,15)$. Gabapentin may also have antidepressant effects: patients on the new AED have noted improvement in mood, memory attention, energy, sleep, and libido $(10,13,17)$. Elevation in mood which accompanied the transition from traditional AEDs to gabapentin, however, may have resulted from discontinuation of the sedating side effects of the traditional agents. Further study is needed to determine if gabapentin has inherent antidepressant effects.

\section{SAFETY}

Gabapentin has proven itself to be a relatively safe drug. The most commonlyencountered side effects are somnolence (24\%), dizziness (20\%), ataxia (17\%), and fatigue (14\%) (19). Less frequent side efforts include involuntary twitches $(1.3 \%)$, rash $(0.5 \%)$, leukopenia $(0.2 \%)$, azotemia $(0.1 \%)$, thrombocytopenia $(0.1 \%)$, stuttering (1 case), and weight gain $(19,21,22)$. There have been several reported cases of hypomania and/or increased mood cycling $(14,15,17,23)$ and there has been one case of oculogyric crisis which was emergently reversed with a benzodiazepine (22).

A therapeutic range for gabapentin has yet to be established. Peak steady-state plasma levels of the drug average about 4 micrograms $/ \mathrm{ml}$ (7). There has been one reported case of overdose, in which a 16-year-old ingested 163 capsules (49,900 mg) without emesis or return of pill fragments on gastric lavage. Her plasma gabapentin level was 62 micrograms $/ \mathrm{ml}$ at 8.5 hours after ingestion. She was lethargic, but was easily aroused and able to converse normally; by 18 hours post-ingestion, she was alert and without complaints (24). This case report is consistent with animal toxicity tests, in which mice and rats experienced only ataxia and labored breathing at maximum dose of $2000 \mathrm{mg} / \mathrm{kg}$ IV and $8000 \mathrm{mg} / \mathrm{kg}$ PO. None of the animals expired (24).

Gabapentin has several properties which significantly reduce its potential for 
interaction with other drugs. It is non-protein-bound, it does not affect hepatic enzyme activity, and it has no metabolites (2). Although clinical trials have not reported any cases of drug-drug interactions involving gabapentin (20), and some sources have suggested that such interactions are impossible $(25,26)$, several reports have suggested that the drug may occasionally affect or be influenced by other medications.

In one study, a therapeutic dose of aluminum and magnesium hydroxide (Maalox), administered concomitantly with or shortly after $400 \mathrm{mg}$ of gabapentin, reduced the bioavailability of the latter by $20 \%$ (27). Cimetidine has reportedly decreased the renal clearance of gabapentin by a clinically significant amount (7). There has been one case report of gabapentin interacting with phenytoin. A patient with a long history of complex partial and secondarily generalized seizures, who was on three AED's, began taking gabapentin. His plasma phenytoin concentration subsequently increased from 42 to 177 micrograms/L and returned to baseline upon removal of the new drug (28). Finally, gabapentin has been assessed as unlikely to cause contraceptive failure when taken with oral contraceptives (7).

There are few reports of pregnant women taking gabapentin. No teratogenic effects have been noted in any of the 10 reports on file (29). The drug is, however, fetotoxic in rodents, associated with delayed ossification, hydroureter, and hydronephrosis at doses up to four times greater than relative standard human dosages (i.e. $3600 \mathrm{mg} / \mathrm{d}$ ). There was also an increased incidence of pancreatic acinar cell tumors in male rats at high doses, though their life span was not affected by the neoplasms (30). Potential uses of gabapentin in the pediatric affective disorders populations have yet to be determined.

\section{DOSING}

Formal dosing guidelines are not available for the use of gabapentin in bipolar disorders. Maintenance doses for seizure control range from 900-2400 mg/d (2,6,19,26) and preliminary trials of gabapentin for mood stabilization seem to suggest a similar dose range. The drug's relatively short half-life necessitates TID administration. Gabapentin treatment for refractory seizures is generally initiated with $300 \mathrm{mg}$ once on the first day, $300 \mathrm{mg}$ twice on the second day and $300 \mathrm{mg}$ three times on the third day, with subsequent increases in TID dose as required for symptom control $(2,19)$.

Of some clinical significance is the fact that all studies to date examining gabapentin in the treatment of bipolar illness have included patients who responded to a dose less than $900 \mathrm{mg} / \mathrm{d}$ (13-18). In one study of 28 patients, the mean gabapentin dose was $539 \mathrm{mg} / \mathrm{d}$ (15). Hence, increasing doses by $200 \mathrm{mg}$ instead of 300 $\mathrm{mg}$ may be more appropriate for mood stabilization.

\section{DISGUSSION}

All of the medications presently used to treat bipolar disorder have significant side effects which impact both quality of life and therapeutic compliance. Unfortu- 
nately, in this patient population, dissatisfaction with treatment regimens has the potential to significantly worsen the patient's clinical course by magnifying feelings of hopelessness in a depressed patient. Gabapentin holds promise as an adjunctive form of treatment which has few inherent disadvantages and little chance of interacting with other drugs. Its favorable pharmacokinetics profile is unique among mood stabilizers. The drug has relatively few side effects, most of which are benign in nature. Its possible antidepressant effects and hypomanic side effects need further study. It has thus far demonstrated low toxicity at therapeutic doses and in overdose. Gabapentin has displayed clinical efficacy in up to $80 \%$ of bipolar patients in preliminary clinical trials, and is presently undergoing investigation as a possible agent in the treatment of migraine headaches, chronic pain, and behavioral disorders. Few reports of gabapentin's use in human pregnancy exist, and animal studies have been somewhat discouraging.

Current psychiatric use of gabapentin is restricted to patients who have failed to respond to traditional agents or developed intolerable side effects from them. The upper limit of the drug's therapeutic range must be established. Problems with medication compliance may be improved through the development of an extendedrelease or depot form of gabapentin. A large, multi center, randomized, controlled clinical trial has yet to be performed.

\section{CONCLUSIONS}

Gabapentin is a GABA analogue and new AED which has the unique ability to cross the blood-brain barrier. It appears to influence neuropsychological activity by acting on calcium channels in the CNS. It has a favorable pharmacokinetics profile and is proving to be relatively safe in clinical practice. The drug has displayed both mood-stabilizing and possible anti-depressant activity in preliminary trials, and is associated with a relatively benign side profile. Further study of this new AED is clearly needed.

\section{REFERENCES}

1. MacDonald RL and Kelly KK: Antiepileptic drug mechanisms of action. Epilepsia 1995; 36(suppl 2):2-12.

2. McLean MJ: Gabapentin. Epilepsia 1995; 36(suppl 2):73-86.

3. Taylor C: Emerging perspectives on the mechanism of action of gabapentin. Neurology 1994; 44(suppl 5):10-16.

4. Loacher W, Honack D. and Taylor CP: Gabapentin increases aminooxyacetic acid-induced GABA accumulation in several regions of rat brain. Neurosci Lett 1991; 128:150-154.

5. Bruni J: Gabapentin. Can J Neurol Sci 1996; 23:10-12.

6. Dubovsky SL, Buzan RD. Novel alternatives and supplements to lithium and anticonvulsants for bipolar affective disorder. J Clin Psychiatry 58:224-242.

7. McLean MJ: Clinical pharmacokinetics of gabapentin. Neurology 1994; 44 (suppl5):17-22.

8. Kumaran TS, Shetty MK, Lynn DJ: Gabapentin for mood instability associated with migraine. New Research Abstracts. 150th Annual Meeting of the American Psychiatric Association 1997; NR130. 
9. Regan WM, Gordon SK: Gabapentin for behavioral agitation in Alzheimer's disease [letter]. J Clin Psychopharm 1997; 17:59-60.

10. Ryback R, Ryback L: Gabapentin for behavioral dyscontrol [letter]. Am J Psychiatry 1995; 152:1399.

11. Roaner K, Rubin L, Kestenbaum A: Gabapentin adjunctive therapy in neuropathic pain states. Clin J Pain 1996; 12:56-58.

12. McGraw T: Erythromelagia pain managed with gabapentin. Anesthesiology 1997; 86:988990.

13. Marcotte DB, Fagelman L, Wolfe N, et al: Gabapentin: An effective therapy for patients with bipolar affective disorder. New Research Abstracts, 150th Annual Meeting of the American Psychiatric Association 1997; NR261.

14. Ryback RS, Brodsky L, Munasifi F: Gabapentin in bipolar disorder [letter]. J Neuropsychiatry 1997; 9:301.

15. Schaffer CB, Schaffer LC: Gabapentin in the treatment of bipolar disorder [letter]. Am J Psychiatry 1997; 154:291.

16. Stanton SP, Keck P, McElroy SL: Treatment of acute mania with gabapentin [letter]. AmJ Psychiatry 1997; 154:287.

17. Young LT, Robb J, Patelis-Siotis I, et al: Gabapentin in bipolar depression: A case series. New Research Abstracts, 150th Annual Meeting of the American Psychiatric Association 1997; NR452.

18. Bennett J, Goldman WT, Suppes T: Gabapentin for treatment of bipolar and Schizoaffective disorders. J Clin Psychopharm 1997; 17:141-2.

19. Ramny RE: Clinical efficacy and safety of gabapentin. Neurology 1994; 44(suppl 5):23-30.

20. Morris GL, "Efficacy and tolerability of gabapentin in clinical practice. Clin Ther 1995; 17:891-900.

21. Nissani M, Sanchez EA: Stuttering caused by gabapentin [letter]. Ann Inten Med 1997; $126: 410$.

22. Reeves AL: Movement disorders associated with the use of gabapentin. Epilepsia 1996; 37:988-990.

23. Short C, Cooke L: Hypomania induced by gabapentin [letter]. Br J Psychiatry 1995; 166:679-680.

24. Fischer JK: Lack of serious toxicity following gabapentin overdose. Neurology 1994; 44:982-983.

25. Matson RK: Efficacy and adverse effects of established and new antiepileptic drugs. Epilepsia 1995; 36(suppl 2):13-26.

26. Wilder BJ: Antiepileptic drugs—current use. Can J Neurol Sci 1996; 23:18-23.

27. Busch, E: Effect of Maalox TC on single dose pharmacokinetics of gabapentin capsules in healthy subjects. Pharm Res 1992 (suppl):315.

28. Tyndel F: Interaction of gabapentin with other antiepileptics. Lancet 1994; 343:1363-1364.

29. Parke Davis, data on file.

30. Gabapentin packaging insert. 